\title{
PREVENTION OF POST INTUBATION SORE THROAT BY USING AN ALKALINIZED LIGNOCAINE FILLED ETT CUFF
}

\section{Ch Anil Kumar ${ }^{1}$, D Sandeep Kumar ${ }^{2}$.}

${ }^{1}$ Assistant professor in Anaesthesia, Viswabharathi medical college, Penchikalapadu, Kurnool, Andhra Pradesh, India.

${ }^{2}$ Senior resident in Anaesthesia, Viswabharathi medical college, Penchikalapadu, Kurnool, Andhra Pradesh, India.

\section{ABSTRACT}

Sore throat is a common postoperative complaint after endotracheal intubation during general anaesthesia. The benefits of using alkalinized lignocaine to fill the cuff of an endotracheal tube to prevent post intubation sore throat were sought. A randomized controlled study was performed on 66 patients of ASA I-II status divided into 3 groups of 22 each. In the A group ETT was filled with air, in group PL plain lignocaine was used to inflate the cuff and in group AL alkalinized lignocaine was used to fill the ETT cuff. The degree of sore throat and other side effects of intubation like coughing, restlessness, dysphonia and hoarseness were assessed over 24 hours post-extubation. In this present study, incidence of sore throat was less when intracuff alkalinized lignocaine was used rather than plain lignocaine or air. Throat pain, restlessness, dysphonia and hoarseness were most common in the air group in which air was the inflating medium. Compared to plain lignocaine group, the incidence of side effects was less in the alkalinized lignocaine group. Thus our study showed benefit of using an alkalinized lignocaine filled ETT cuff in preventing post intubation sore throat.

KEY WORDS: Postoperative, Alkalinized lignocaine, Sore throat, Coughing, Restlessness, Dysphonia and Hoarseness.

Address for correspondence: Dr. D Sandeep Kumar, Address: Department of Anaesthesia, Viswabharathi medical college, Penchikalapadu, Kurnool, Andhra Pradesh, India.

E-Mail: sandeep2452@gmail.com

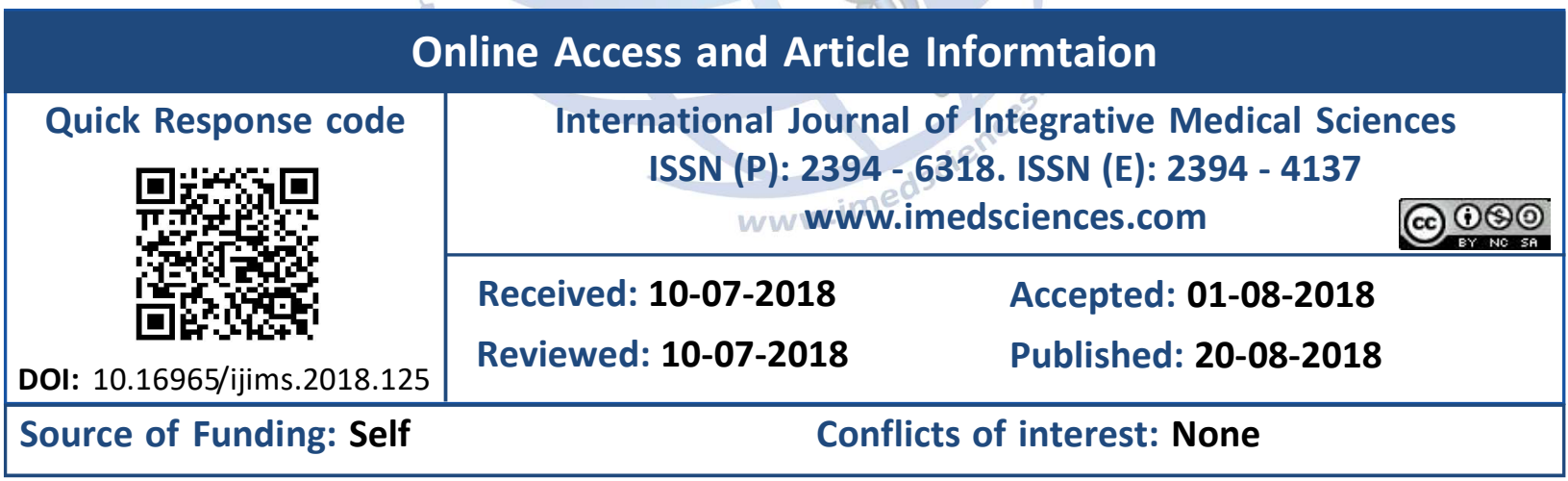

\section{BACKGROUND}

Postoperative sore throat occurs in $30-70 \%$ (up to $90 \%$ in some studies) of intubated patients and it is the most common complaint after tracheal intubation [1]. Coughing during emergence from General Anaesthesia can result in hypertension, tachycardia, increased intraocular and intracranial pressures, myocardial ischemia, bronchospasm and surgical bleeding. Laryngeal edema and ischemia are also commonly associated with intubations [2]. The aetiology of sore throat is thought to involve mucosal erosion caused by the cuff of the endotracheal tube, trauma from intubation, and mucosal dehydration [3]. Rapidly adapting stretch receptors (RAR) in the tracheal mucosa are believed to be irritant receptors involved in the cough reflex [4-5]. Lignocaine, if used as intracuff agent, can suppress these side effects. Mechanism of lignocaine diffusion across an Endo tracheal tube (ETT) cuff is similar to that found in epidural space [6]. Lignocaine exists in two forms, non-ionized free base and ionized cation. An increase in non-ionized fraction of lignocaine results in improved penetration and better diffusion across the cuff. Increasing the 
$\mathrm{pH}$ of the solution can predictably increase the percentage of the non-ionized form [7]. Earlier studies have proved that alkalinization of lignocaine increases the diffusion capacity across the ETT cuff. Increasing the alkalinity of the local anaesthetic using sodium bicarbonate also dramatically increases its diffusion through the ETT cuff [8].

As there is a significant incidence of sore throat in patients postoperatively, this study emphasizes the epidemiological importance of measures that can reduce post intubation morbidity. Estebe jp et al. [8] reported that patients with postoperative sore throat had a negative impression of anaesthesia practice. Therefore current study was taken up with the aim of preventing postoperative sore throat. This study was designed to compare the incidence of post-intubation sore throat when intracuff alkalinized lignocaine, plain lignocaine and air were used.

\section{MATERIALS AND METHODS}

After obtaining institutional ethical committee clearance, data was collected from patients (ASA $-I / I I)$ scheduled for major surgical procedures lasting between 2-5 hrs, aged between 20-60 years both the sex, who are willing to participate in this study were included. Documented hypersensitivity to lignocaine, predicted difficult intubation, Patients who could not be intubated in the first attempt, history of recent sore throat, trachetis or laryngitis, Bronchial Asthma and COPD, chronic smoking, Patients requiring the insertion of a nasogastric tube, Patient to be electively ventilated after surgery, and Patients undergoing oropharyngeal surgeries were not included in the present study cared out at Department of anesthesiology and critical care, Narayana Hrudayalaya, (Mazumdar Shaw Medical Centre) Bangalore. Written informed consent was taken from all patients. The study was a double blind study and simple randomiszation was done using numbers generated by a computer programme by co-investigator .The patient and principle investigators (observer) are blinded. The different groups of study were:

- Group A ETT cuff was filled with air

- Group PL ETT cuff was filled with plain lignocaine.
- Group AL ETT cuff was filled with alkalized lignocaine.

- Each group had 22 patients aged between 20-60 years and belonging to ASA I/II.

\section{Anaesthetic Management:}

Propofol(1-2 mg/kg), Fentanyl $(2 \mu \mathrm{g} / \mathrm{kg})$ and vecuronium / atracurium was used for intra venous induction and inhalational agents used were isoflurane and nitrous oxide. Endotracheal intubation was performed using an appropriate sized ETT with a high volume low-pressure cuff. The ETT cuff was inflated to the minimal occlusive volume (prevents aspiration and gas leak). In group A cuff was inflated with air in the group AL cuff was inflated with a mixture of $2 \%$ lignocaine and $8.4 \%$ sodium bicarbonate (10:1) to obtain minimum occlusive volume and then 2 $\mathrm{ml}$ of same mixture added and in group $\mathrm{PL}$, cuff is filled with $2 \%$ lignocaine to obtain minimal occlusive volume and then $2 \mathrm{ml}$ of $2 \%$ lignocaine added. Maintenance of anaesthesia was with inhalational agents and intermittent doses of fentanyl and muscle relaxant. The anaesthetic team was unaware of the experimental protocol. Reversal of neuromuscular blockade was $\mu$ done with neostigmine and glycopyrrolate.

Patients were extubated after all the following criteria are met- full reversal of neuromuscular blockade, spontaneous ventilation and ability to follow verbal commands, eye opening and sustained hand grip for 5 second. Cough reflex and restlessness were checked before extubation and for $24 \mathrm{hrs}$ after extubation (1hr, $2 \mathrm{hr}$, $12 \mathrm{hr}$, and $24 \mathrm{hrs})$. The degree of sore throat was assessed in the post operative recovery room using a visual analogue scale (VAS 0-100 mm). Patients were asked to point at different facial expressions depicted on the VAS scale which quantified different degrees of pain. Other evidence of throat discomfort such as cough, hoarseness, restlessness, and dysphonia was evaluated and hemodynamic parameters were recorded. The volume of air or liquid used to inflate the cuff was noted and the volume retrieved during extubation was also recorded.

\section{Statistical analysis:}

Data was pooled and continuous variables expressed as mean and standard deviations, categorical variables were described as 
frequency and percentage. Comparison between data was done by the Analysis of variance with bonferroni correction or Kruskal Wallis test. Chi-square and $2 \times 3$ Fisher exact test was used

\section{RESULTS}

Table 1: Basic characteristics of the study and Comparison of Volume (Milli liters) in three groups of patients Results are presented in Mean \pm SD.

\begin{tabular}{|c|c|c|c|c|}
\hline $\begin{array}{c}\text { Basic } \\
\text { characteristics }\end{array}$ & Air Group & PL Grop & AL Group P & p value \\
\hline $\begin{array}{c}\text { Age in years } \\
\text { (Mean } \pm \text { SD) }\end{array}$ & $36.7 \pm 9.72$ & $38.1 \pm 10.1$ & $36.4 \pm 10.8$ & 0.835 \\
\hline Male / Female & $8: 14$ & $10: 12$ & $8: 14$ & 0.776 \\
\hline $\begin{array}{c}\text { Duration of } \\
\text { Procedure in } \\
\text { minutes }\end{array}$ & $156 \pm 27.8$ & $149.2 \pm 22.7$ & $144.1 \pm 23.3$ & 0.267 \\
\hline For inflation & $3.83 \pm 0.38$ & $3.77 \pm 0.28$ & $3.8 \pm 0.29$ & 0.825 \\
\hline After deflation & $4.34 \pm 0.44$ & $3.36 \pm 0.28$ & $3.05 \pm 0.32$ & $<0.001 * *$ \\
\hline
\end{tabular}

Table 2: mean, SD and Comparision of Pulse rate $(\mathrm{bpm}), \mathrm{SBP}(\mathrm{mmHg})$, and SBP $(\mathrm{mmHg})$ in three groups of patients.

\begin{tabular}{|c|c|c|c|c|c|c|c|c|}
\hline \multicolumn{3}{|c|}{ Study period } & Pre-op & During & At 1 hour & At 2 hour & At 12 hour & At 24 hour \\
\hline \multirow{7}{*}{$\begin{array}{c}\text { Pulse rate } \\
\text { (bpm) }\end{array}$} & \multirow{2}{*}{ Air Group } & Mean & 82.18 & 98.72 & 82.5 & 78.9 & 77.7 & 76.1 \\
\hline & & SD & 12.77 & 12.52 & 8.92 & 7.92 & 8.15 & 8.04 \\
\hline & \multirow{2}{*}{ PL Group } & Mean & 83.7 & 92.73 & 79.8 & 77.9 & 78.9 & 77.6 \\
\hline & & SD & 10.92 & 9.35 & 9.49 & 10.2 & 9.66 & 8.43 \\
\hline & \multirow{2}{*}{ AL Group } & Mean & 84 & 88.91 & 83.8 & 80.9 & 79 & 78.1 \\
\hline & & SD & 11.09 & 9.07 & 10.4 & 10.1 & 10 & 9.67 \\
\hline & \multicolumn{2}{|c|}{ p value } & 0.857 & $0.01 * *$ & 0.37 & 0.56 & 0.88 & 0.732 \\
\hline \multirow{7}{*}{$\begin{array}{c}\text { SBP } \\
(\mathrm{mmHg})\end{array}$} & \multirow{2}{*}{ Air Group } & Mean & 122.6 & 139.82 & 124 & 122 & 122 & 123 \\
\hline & & SD & 13.17 & 11.4 & 12.6 & 12.2 & 11.1 & 10.5 \\
\hline & \multirow{2}{*}{ PL Group } & Mean & 121.5 & 131.91 & 124 & 123 & 123 & 124 \\
\hline & & SD & 11.92 & 11.93 & 10.8 & 10.5 & 9.61 & 10.5 \\
\hline & \multirow{2}{*}{ AL Group } & Mean & 122.6 & 129.18 & 126 & 125 & 123 & 124 \\
\hline & & SD & 12.04 & 10.74 & 11.9 & 11.9 & 12.1 & 12.7 \\
\hline & \multicolumn{2}{|c|}{ p value } & 0.939 & $0.00 * *$ & 0.817 & 0.834 & 0.959 & 0.976 \\
\hline \multirow{7}{*}{$\begin{array}{c}\text { DBP } \\
\text { (mmHg) }\end{array}$} & \multirow{2}{*}{ Air Group } & Mean & 77.55 & 84.64 & 76.9 & 75 & 76 & 74.5 \\
\hline & & SD & 6.76 & 7.72 & 4.13 & 4.97 & 4.54 & 4.09 \\
\hline & \multirow{2}{*}{ PL Group } & Mean & 76.18 & 79.27 & 74.3 & 73.7 & 74.2 & 73.4 \\
\hline & & SD & 7.27 & 7.26 & 6.03 & 5.7 & 5.45 & 5.7 \\
\hline & \multirow{2}{*}{ AL Group } & Mean & 76.73 & 78 & 76.8 & 75.8 & 74.6 & 74.8 \\
\hline & & SD & 5.87 & 5.16 & 5.37 & 4.93 & 5.1 & 4.6 \\
\hline & \multicolumn{2}{|c|}{$p$ value } & 0.791 & $0.004 * *$ & 0.173 & 0.413 & 0.465 & 0.585 \\
\hline
\end{tabular}

Table 3: Comparison of Pain scores in three groups of patients (Results based on VAS score).

\begin{tabular}{|c|c|c|c|c|c|c|c|}
\hline \multirow{2}{*}{ Study Period } & \multicolumn{2}{|c|}{ Air Group } & \multicolumn{2}{c|}{ PL Group } & \multicolumn{2}{c|}{ AL Group } & p value \\
\cline { 2 - 9 } & Mean & SD & Mean & SD & Mean & SD & \\
\hline At 1 hour & 6.05 & 0.89 & 5.68 & 0.78 & 4.32 & 1.69 & $<0.001^{* *}$ \\
\hline At 2 hour & 5 & 1.07 & 4.68 & 0.89 & 3.36 & 1.49 & $<0.001^{* *}$ \\
\hline At 12 hour & 4.05 & 0.84 & 3.68 & 0.57 & 2.41 & 0.92 & $<0.001^{* *}$ \\
\hline At 24 hour & 3 & 0.76 & 2.5 & 0.67 & 1.36 & 0.49 & $<0.001^{* *}$ \\
\hline
\end{tabular}


Table 4: Comparison of incidence of Cough and Restlessness in three groups of patients Results are presented in number (\%).

\begin{tabular}{|c|c|c|c|c|c|c|}
\hline \multicolumn{2}{|c|}{ Study period } & $\begin{array}{c}\text { During } \\
\text { extubation }\end{array}$ & At 1 hour & At 2 hour & At 12 hour & At 24 hour \\
\hline \multirow{5}{*}{ Cough } & Air Group & $20(90.91 \%)$ & $17(77.27 \%)$ & $13(59.09 \%)$ & $7(31.82 \%)$ & $4(18.18 \%)$ \\
\cline { 2 - 8 } & PL Group & $14(63.64 \%)$ & $11(50.00 \%)$ & $7(31.82 \%)$ & $5(22.73 \%)$ & $1(4.55 \%)$ \\
\cline { 2 - 8 } & AL Group & $10(45.45 \%)$ & $7(31.82 \%)$ & $4(18.18 \%)$ & 0 & 0 \\
\cline { 2 - 8 } & p value & $0.005^{* *}$ & $0.009 * *$ & $0.006 * *$ & $0.01 *$ & 0.155 \\
\hline \multirow{5}{*}{ Restlessness } & Air Group & $18(81.82 \%)$ & $14(63.64 \%)$ & $6(27.27 \%)$ & $4(18.18 \%)$ & $2(9.09 \%)$ \\
\cline { 2 - 8 } & PL Group & $15(68.18 \%)$ & $5(22.73 \%)$ & $4(18.18 \%)$ & $3(13.64 \%)$ & $2(9.09 \%)$ \\
\cline { 2 - 8 } & AL Group & $10(45.45 \%)$ & $5(22.73 \%)$ & 0 & 0 & 0 \\
\cline { 2 - 8 } & p value & $0.04 *$ & $0.005^{* *}$ & $0.007^{* *}$ & $0.04 *$ & 0.177 \\
\hline
\end{tabular}

Table 5: Comparison of Dysphonia, Hoarseness, and Sore throat in three groups of patients Results are presented in number (\%).

\begin{tabular}{|c|c|c|c|c|c|}
\hline \multicolumn{2}{|c|}{ Study period } & Air Group & PL Group & AL Group & p value \\
\hline \multirow{5}{*}{ Dysphonia } & At 1 hour & $7(31.82 \%)$ & $5(22.73 \%)$ & $3(13.64 \%)$ & 0.355 \\
\cline { 2 - 6 } & At 2 hour & $8(36.36 \%)$ & $1(4.55 \%)$ & 0 & $<0.001^{* *}$ \\
\cline { 2 - 6 } & At 12 hour & $6(27.27 \%)$ & $1(4.55 \%)$ & 0 & $0.007^{* *}$ \\
\cline { 2 - 6 } & At 24 hour & $5(22.73 \%)$ & $1(4.55 \%)$ & 0 & $0.02^{*}$ \\
\hline \multirow{5}{*}{ Hoarseness } & At 1 hour & $13(59.10 \%)$ & $6(27.27 \%)$ & $5(22.73 \%)$ & $0.024^{*}$ \\
\cline { 2 - 7 } & At 2 hour & $9(40.91 \%)$ & $4(18.18 \%)$ & $1(4.55 \%)$ & $0.01^{* *}$ \\
\cline { 2 - 7 } & At 12 hour & $7(31.82 \%)$ & $1(4.55 \%)$ & 0 & $0.002^{* *}$ \\
\cline { 2 - 7 } & At 24 hour & $4(18.18 \%)$ & 0 & 0 & $0.01^{*}$ \\
\hline & At 1 hour & $9(40.91 \%)$ & $7(31.82 \%)$ & $4(18.18 \%)$ & 0.256 \\
\cline { 2 - 7 } & At 12 hour & $12(54.55 \%)$ & $8(36.36 \%)$ & $3(13.64 \%)$ & 0.017 \\
\cline { 2 - 7 } & At 24 hour & $14(63.64 \%)$ & $5(22.73 \%)$ & $1(4.55 \%)$ & $<0.001^{* *}$ \\
\hline
\end{tabular}

\section{DISCUSSION}

The present study was undertaken to compare the effect of plain lignocaine and alkalinized lignocaine when used as inflating medium instead of air in ETT cuff to prevent postoperative sore throat. There were no statistically significant differences among patients from the three groups regarding age, sex and duration of surgery (Table 1). There were no problems with the cuff inflation and no air leak was recorded during controlled ventilation. There was no difference in the initial volume of liquid injected into the cuff for group PL and AL (3.77 vs. 3.80). The volume of liquid removed from the cuff was lesser in group AL compared to group PL (3.05 vs. 3.36).The gas volume withdrawn at extubation- increased significantly in the air group (4.34 \pm 0.44$), p<0.001$ (Table 1). Previous studies have showed increased cuff pressure and volume over time after air inflation. During anaesthesia using nitrous oxide, the cuff pressure increases as the temperature of the cuff rises and nitrous oxide diffuses into it more rapidly than it leaves (9).This over inflation of the ETT has been associated with damage to pharyngeal mucosa and recurrent laryngeal nerve palsy [10]. It would also cause increased receptor stimulation in the tracheal mucosa and thus increase emergence and extubation phenomena. The complication was decreased by filling the ETT cuff with liquid [11,12].

In the present study it was observed that the initial air volume required to inflate the cuff was slightly greater than the liquid volume in PL group. At the time of extubation air volume in the cuff increased owing to diffusion. In the groups $P L$ and $A L$ there was no significant difference in the volume of liquid required to inflate the cuff. In the group AL, the volume of liquid removed from the cuff was lesser. These results are in agreement with previous studies on in vivo diffusion of lignocaine across the ETT cuff. The current results also reinforce the assumption that nitrous oxide is the principal 
causative factor of overpressure in the ETT cuff during balanced anaesthesia.

In the present study heart rate increased in all three groups during extubation. The increase was higher in the air group, while there was no difference in the PL and AL group. The heart rate returned to preoperative value in all three groups after one hour. The blood pressure increased in three groups during extubation. The increase was highest in the air group followed by PL and AL group. Blood pressure returned to pre operative value in all groups 1-2 hours after extubation. (Table 2).

In the present study $90.91 \%$ of subjects in the air group had cough at extubation and it decreased to $77.27 \%$ at 1 hour. In PL group, 50\% subjects had cough while in AL group 31.82\% subjects had cough. Cough gradually decreased in all three groups. At 24 hours post-extubation 4 subjects had cough in the air group, 1 subject in the PL group. There was no incidence of cough in the AL group after 12 hours (Table 4). Previous studies have shown that lignocaine acts locally on tracheal mucosa and reduces ETT induced coughing during emergence from general anaesthesia.

In the present study, at extubation $81.82 \%$ subjects in air group, $68.18 \%$ subjects in PL group and $45.45 \%$ subjects in AL group had restlessness. There was no incidence of restlessness in the AL group at 2 hours after extubation. Restlessness decreased in both $A$ and PL group over 24 hours (Table 4). Dysphonia was seen in $31.82 \%$ of subjects of air group after 1 hour and it decreased to $22.73 \%$ at 24 hours. In PL group, $22.73 \%$ subjects had dysphonia at 1 hour postextubation and only 1 subject had it at 24 hours. In AL group, $13.64 \%$ subjects had dysphonia at 1 hour and there was no incidence of dysphonia after that (Table 5). At 1 hour, post-extubation hoarseness was present in $59.10 \%$ of subjects in the air group, $27.27 \%$ subjects in PL group and $22.73 \%$ subjects in AL group. There was no incidence of hoarseness in AL group after 12 hours (Table 5). .

Throat pain was assessed using a VAS scale. Throat pain was highest in the air group. At 1 hour post extubation pain was less in the $A L$ group compared to PL group. Throat pain decreased gradually over 24 hours in all three Int J Intg Med Sci 2018;5(7):693-99. ISSN 2394 - 4137 groups. There was statistically significant difference in pain scores between air group and the other groups $P$ value $<0.001$ (Table 3 ). Restlessness and cough were more common in the air group. Incidence of restlessness was less in the AL group compared to the PL group. After 1 hour, there was no incidence of restlessness in AL group. Dysphonia and hoarseness was more pronounced in the air group. Incidence of hoarseness was more in the PL group than in $\mathrm{AL}$ group.

In the present study when compared, Sore throat was observed in $54.55 \%$ subjects in A group, $36.36 \%$ subjects in PL group and in $13.64 \%$ subjects among AL group at end of 12 hours. This is statistically significant $(P=0.017)$. At the end of 24 hours the incidence of sore throat is $63.64 \%, 22.73 \%$ and $4.55 \%$ in A group, PL group and AL group respectively. This is statistically significant with $P$ value of $<0.001$ (Table 5). A general anaesthetic technique that would allow patients to have a comfortable postoperative period is highly beneficial. This study was designed to compare the incidence of post intubation sore throat when intracuff alkalinized lignocaine was used compared to intracuff plain lignocaine. The principal finding of our study was that the incidence of post intubation sore throat decreased when alkalinized lignocaine was used to inflate the ETT cuff rather than plain lignocaine or air. Coughing during emergence from general anaesthesia may be undesirable in certain clinical situations. Although previous studies indicate that intravenous lignocaine in doses of $1.0-2.0 \mathrm{mg} / \mathrm{kg}$ transiently suppresses coughing and other airway reflexes in humans in several settings [13-19]. Certain features limit its clinical usefulness as a cough suppressant during emergence from general anaesthesia. First, the plasma lignocaine level necessary to effectively suppress coughing is fairly high $(3 \mu \mathrm{g} / \mathrm{ml})$. Second, systemic lignocaine may produce sedation and prolong emergence from anaesthesia. Infact a plasma lignocaine concentration of only $1 \mathrm{~g} / \mathrm{ml}$ decreases halothane minimum alveolar concentration requirements in animals by approximately $40 \%$ (16).

When $2 \mathrm{mg} / \mathrm{kg}$ of lignocaine was injected intravenously between 1 and 5 min before attempting intubation, cough reflex was suppressed 
completely by increasing of plasma concentrations of lignocaine in excess of 3 micrograms/ $\mathrm{ml}[20-23]$.

In the present study we found that incidence of sore throat was less when intracuff alkalinized lignocaine was used rather than plain lignocaine. Throat pain, restlessness, dysphonia and hoarseness were most common in the $A$ group in which air was the inflating medium. Compared to $\mathrm{PL}$ group, the incidence of side effects was less in the AL group. This was significant and comparable with previous studies as follows. During artificial ventilation using a mixture of oxygen and nitrous oxide, inflation of tracheal tube cuffs of large residual volume and low pressure using $2 \%$ alkalinized lignocaine, in comparison with cuffs inflated with air, prevented the occurrence of a significant rise in cuff pressure and gave rise to greater tracheal tube tolerance and lower incidence of postoperative sore throats. Aside from that, it promoted a significantly smaller rise in systolic arterial pressure immediately after tracheal extubation [24].

\section{CONCLUSION}

The present study demonstrated a significant decrease in the incidence of sore throat during the postoperative period when the cuff of an ETT was inflated with alkalinized lignocaine rather than plain lignocaine or air and incidence of side effects of tracheal intubation were less when inflating medium of ETT cuff was alkalinized lignocaine, rather than plain lignocaine or air. Thus, alkalinized lignocaine-filled ETT cuffs seem to be safer compared to conventional air filled ETT cuffs.

\section{REFERENCES}

[1]. Lev R, Rosen P. Prophylactic lignocaine use preintubation: a review. J Emerg Med 1994; 4: 499-506.

[2]. Bidwai AV, Bidwai VA, Rogers CR, Stanley TH. Blood pressure and pulse rate responses to endotracheal extubation with and without prior injection of lignocaine. Anesthesiology 1975; 51: 171-3.

[3]. Combes X, Schauvliege F, Peyrouset O, Motamed C, Kirov K, Dhonneur G, etal. Intracuff pressure and tracheal morbidity: influence of filling with saline during nitrous oxide anesthesia. Anesthesiology2001;95(5):1120-4.

[4]. Bartlett D Jr. Jeffrey P, SantsAmbrogio G, Wise JC. Location of stretch recetors in the tracheal and bronchi of the dog. J Physiology (Lond) 1976; 258: 40920.

Int J Intg Med Sci 2018;5(7):693-99. ISSN 2394 - 4137
[5]. Camporesi EM. MortolaJP.Sant' Ambrogio F, Sant'sAmbrogio G. Topical anaesthesia of tracheal receptors. J ApplPhysiol 1979; 47: 1123-6.

[6]. De Joy RH. The minimum blocking concentration in: De Jong RH (Ed) Local anaesthetics. Springfield, Illinois: Charles C Thomas. 1977:51-62

[7]. Butterworth JF, Strichartz GR. Molecular mechanism of local anaesthetics: a review. Anesthesiology 1990; 72: 711-34.

[8]. Estebe JP, Dollo G, Le Corre, Le Naoures A, Chervanne $F$, Le verge $R$,etal. Alkalinization of intracuff lignocaine improves endotracheal tube-induced emergence phenomena. AnesthAnalg. 2002; 94(1):22730.

[9]. Matias E, Steen SN. Diffusion of lignocaine across the cuff of endotracheal tubes. Anesthesia and Analgesia.March 1994. 78(2 suppl): Abstract S 270.

[10]. Sconzo JM, Moscicki JC, DiFazio CA. In vitro diffusion of lignocaine across endotracheal tube cuffs. Reg Anesth 1999; 15:37-40.

[11]. Combes X, Schauvlleje F, Peyrouset O, Motamed C, Kirov K, Dhonneur $G$ et al. Intracuff pressure and tracheal morbidity, influence of filling with saline during nitrous oxide anaesthesia. Anesthesiology 2001; 95: 1120-4.

[12]. Ahmad NL, Norsidah AM. Change in endotracheal tube cuff pressure during nitrous oxide anaesthesia: A comparison between air and distilled water cuff inflation. Anaesth Intensive Care 2001; 29: 5104.

[13]. Seegobin RD, Hasselt GL. Endotracheal cuff pressure and tracheal mucosal blood flow; endoscopic study of effects of large volume cuffs. Br Med J 1984; 288: 965-8.

[14]. Navarro RM, Baughman VL. Lignocaine in the endotracheal tube cuff reduces postoperative sore throat. J ClinAnaesth 1997; 9: 394-7.

[15]. Altintas F, Bozkurt P, Kaya G, Akkan G. Lignocaine $10 \%$ in the endotracheal tube cuff: Blood concentration, hemodynamic and clinical effects. Eur J Anaesthesiol 2000; 17: 436-42.

[16]. Bennett MH, Isert PR, Cumming RG. Postoperative sorethroat and hoarseness following tracheal intubation using air or saline to inflate the cuff: A randomized control trial. AnaesthInten Care 2000; 28: 408-13.

[17]. Matias E. Effect of $\mathrm{NaHCO} 3$ on the diffusion of lignocaine through the wall of endotracheal tube cuff. Br J Anaesth 1995; 74: A-238.

[18]. Dollo G, Estebe JP, Le Corre P, Chevanne F, Ecoffy C, Le Verge R. Endotracheal tube cuff filled with lignocaine as a drug delivery system: In vitro and in vivo investigations. Eur J Pharm Sci 2001; 13: 319-23.

[19]. Steinhaus JE, Gaskin I. A study of intravenous lignocaineas a suppressant of cough reflex. Anesthesiology 1963; 24:285-90.

[20]. Gefke K, Andersen LW, Friesel E.Lignocaine given intravenously as suppressant of cough and laryngospasm in connection with extubation. After tonsillectomy. ActaAnaesthesiolScand 1983; 27:1112. 
[21]. Christenson V, Ladegaard-Pedersen HJ, Skovsted P. Intravenous lignocaine as a suppressant of persistent cough caused by bronchoscopy. ActaAnaesthesiolScandSuppl 1978; 67: 84-6.

[22]. Yukioka H, Yoshimoto N, Nishimura K, Fujimori M .Intravenous lignocaine as a suppressant of coughing during tracheal intubation.AnesthAnalg 1985; 64: 1189-92.

[23]. Nishino T, Hiraga K, Sugimori K. Effects of i.v lignocaine on airway reflexes elicited by irritation of the tracheal mucosa in humans anesthetized with enflurane. Br J Anaesth 1990; 64: 682-7.
[24]. Lais HC Navarro, Jose reinaldo Cerqueira Braz, Giane Nakamura, Rodrigo Moreina e Lima, Fredson de Paula e Silva, Norma Suvli Pinheire Modolo. Effectiveness and safety of endotracheal tube cuffs filled with air versus filled with alkalinized lignocaine: a randomized clinical trial LaisSao Paulo Med J. 2007;125(6):322-8.

How to cite this article: Ch Anil Kumar, D Sandeep Kumar. PREVENTION OF POST INTUBATION SORE THROAT BY USING AN ALKALINIZED LIGNOCAINE FILLED ETT CUFF. Int J Intg Med Sci 2018;5(7):693-699. DOI: 10.16965/ijims.2018.125 